Research Article

\title{
An Optimization Model of Raw Material Supply Chain Using Improved Genetic Algorithm for Primary and Secondary School Uniform under IoT Environment
}

\author{
Yumei Cui $\mathbb{i}$ and Xinqun Feng $(\mathbb{D}$ \\ College of Fashion and Design, Donghua University, Shanghai 200051, China \\ Correspondence should be addressed to Xinqun Feng; fengfeng@dhu.edu.cn
}

Received 23 September 2021; Accepted 26 October 2021; Published 12 November 2021

Academic Editor: Sang-Bing Tsai

Copyright (C) 2021 Yumei Cui and Xinqun Feng. This is an open access article distributed under the Creative Commons Attribution License, which permits unrestricted use, distribution, and reproduction in any medium, provided the original work is properly cited.

\begin{abstract}
With the development of intelligent technology, the life cycle of products is becoming shorter and shorter. The traditional mode of supply chain selection cannot meet the demand of productivity development. Scientific and reasonable choice of school uniforms' raw material supply chain is a necessary condition to assist school's normal operation. Therefore, an optimization model for primary and secondary school clothing raw material supply chain based on the internet of things is proposed. In order to optimize the raw materials supply chain of primary and secondary school uniform, a model based on the internet of things is proposed. In the environment of the internet of things, from the perspective of supply chain configuration and enterprise's expected risk minimization, this paper establishes the optimization model of raw material supply chain of primary and secondary school uniform based on the internet of things. Through the improved genetic algorithm to solve the model, the best raw material supply chain of primary and secondary school uniform is obtained. The simulation results show that the proposed model can effectively improve the asset utilization and execution efficiency of the supply chain and reduce the cost of the raw material supply chain of primary and secondary school uniform.
\end{abstract}

\section{Introduction}

As a professional uniform, school uniform not only has the unity and functionality of ordinary professional uniform but also has the unique personality and characteristics of school uniform. For example, school uniforms pay more attention to the characteristics of different age groups in the choice of color and pay more attention to comfort and green in the selection of fabric, which is also conducive to promoting the psychological growth of primary and secondary school students. School uniform is not only an external manifestation of students' identity but also the embodiment of school management concept and education and also a symbol of national characteristics and culture. In China, it began to be popularized on a large scale in 1993. After more than 20 years of development, the school uniform of primary school students at this stage is mainly sportswear. Compared with other countries, especially developed countries, there is still a big gap.

With the continuous progress and development of society, the communication between people has become more and more smooth. The gap between China's school uniform and other countries has been gradually recognized by more people, and the school uniform culture has attracted more and more attention [1]. In China, some experts call for the improvement of school uniforms, but there are still some people who are against the school uniform system and think that the school uniform system stifles the students' ability of self-creation. At present, different primary and secondary school uniforms have different degrees of attention; in domestic, some private primary schools pay more attention to school uniforms, and some schools improve school uniforms but only in the style as far as possible, and there are still some deficiencies in color and fabric. At this stage, how 
to select the best raw material supply chain of the primary and secondary school uniform has become a hot topic. Relevant experts have given some good research results. For example, Qin et al. [2] set the total cost minimization as the goal, formed the data generation criteria, and used CPLEX to solve the problem so as to effectively realize the supply chain optimization; in the centralized decision-making mode, Chen et al. [3] made effective decisions to obtain the lowest total cost around the four-level supply chain, established fuzzy rules and set decision-making model, and used the fuzzy possibility theory to solve the model to obtain the optimal raw materials supply chain of primary and secondary school uniform. Wang et al. [4] established a supply chain optimization model with the primary objective of minimizing social losses and obtained the optimal supply chain combination under the lowest cost material supply chain combination. The above research results can optimize the supply chain, but in practical application, the cost control and resource utilization still need to be further optimized.

Based on the above research results, this paper proposes a model based on the internet of things for the raw materials supply chain selection of primary and secondary school uniform. The simulation results show that the proposed model can comprehensively improve the asset utilization and execution efficiency of the supply chain and reduce the cost of the raw material supply chain of primary and secondary school uniform.

\section{Methods}

2.1. Establishment of the Optimization Model for Raw Material Supply Chain. The raw material supply chain management of primary and secondary school uniform mainly uses the supply chain relationship and process to carry out business integration and enhance the competitiveness of enterprises. A successful supply chain needs to make a lot of decisions related to information flow, product flow, and capital flow. According to the duration of decisionmaking, decision-making can be divided into three different stages, as shown in Figure 1.

2.1.1. Strategy Stage of Supply Chain. That is, the supply chain design stage is a long-term decision-making process, which can last for several years. At this stage, it is necessary to determine the network structure of supply, production, and downstream distribution in the supply chain through the product BOM [5].

2.1.2. The Planning Stage of Supply Chain. It is the overall planning and coordination stage of the supply chain. The whole stage is mainly responsible for providing mediumand long-term operation plans for the planned supply chain.

2.1.3. Operation Stage of Supply Chain. That is, each execution stage of the supply chain node is mainly responsible for short-term operation decisions.
For manufacturing enterprises, in order to obtain the best raw materials for primary and secondary school uniform, it is necessary to reduce the supply risk of raw materials in the process of practical application. The advantages and disadvantages of the supplier are analyzed according to the following principles:

(1) Primary and secondary schools should select as many suppliers as possible:

Due to the different types of raw materials, enterprises need to select two or three suppliers as the core suppliers, which can effectively avoid enterprises relying too much on the same supplier and reduce the risk of the enterprise supply chain.

In addition, the number of suppliers selected by the enterprise should not be too many. If the supplier selected by the enterprise is a single supplier; when the supplier is out of stock or delayed, it will cause interference to the normal production of the enterprise, and the corresponding risk of the enterprise will also increase correspondingly. On the contrary, if the number of suppliers selected by the enterprise is large, the management cost will also increase. Therefore, we need to pay attention to the number of suppliers and optimize the number of suppliers reasonably.

(2) Using product quality and price level to evaluate suppliers comprehensively:

At present, in the process of selecting suppliers, enterprises need to give priority to price $[6,7]$. In the process of selecting suppliers, enterprises with favorable prices and high-quality raw materials need to be selected as suppliers. If the enterprise takes the price as the only index to measure the supplier, it will have an adverse impact on the enterprise representatives. Therefore, it needs to combine a number of evaluation indicators for a comprehensive evaluation, such as product price, product quality, and so on. We also need to comprehensively consider the cost performance of products. When encountering more special circumstances, under the condition that the enterprise meets the demand of raw material quality, it can also select the supplier through the optimal price.

(3) Paying attention to the suppliers who can provide large quantities of raw materials stably for a long time:

When the production enterprise is in a stable state of development, it is necessary to give priority to the suppliers with large supply and high quality, especially the suppliers who can provide nuclear raw materials for the enterprise [8]. With the continuous increase of enterprise production scale, the production capacity of each enterprise will also increase, and the production of raw materials will also increase. If the supplier is in an unstable and unreliable state for a long time, it will have an adverse impact on the production and development of the enterprise. 


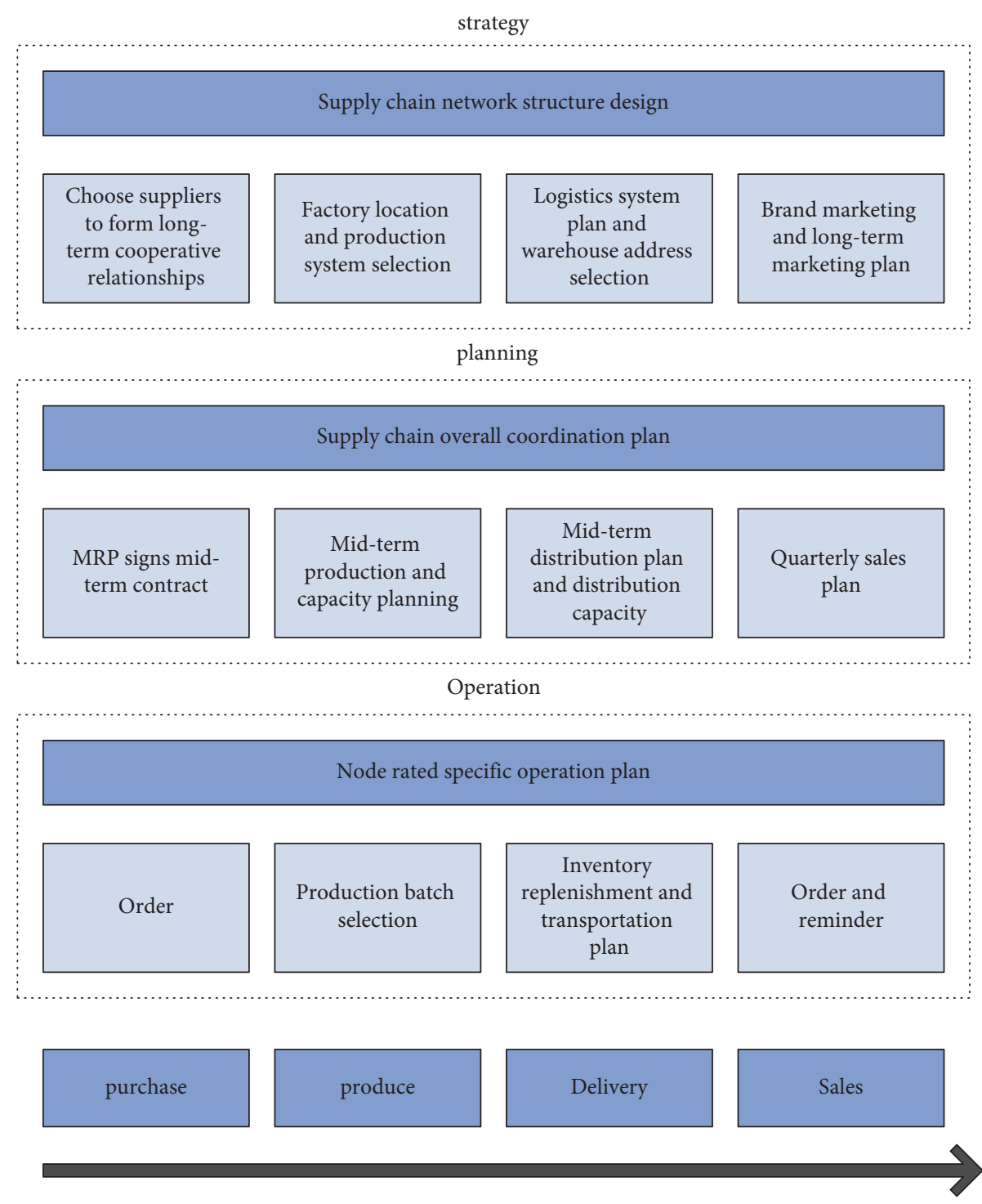

FIGURE 1: Strategic diagram of the three-tier structure of primary and secondary school uniform's raw material supply chain.

(4) Selection of suppliers that match the scale of the enterprise:

Usually, when an enterprise is in the early stage of development, it needs to select the supplier with the appropriate scale. With the continuous development and growth of enterprises, some small suppliers cannot meet the development needs of enterprises. At this time, enterprises need to select new suppliers. However, due to the long-term cooperation between the enterprise and the early suppliers, the replacement of suppliers will bring varying degrees of losses and security risks to the enterprise. On the issue of supplier replacement, enterprises need to combine their own production scale and development situation to make reasonable planning for implementation.

(5) The principle of giving consideration to all aspects and highlighting key points:
Different enterprises have their own supplier evaluation index and evaluation system, but the specific evaluation standard needs to be set by referring to the information to ensure that it can fully reflect the comprehensive level of suppliers at this stage. In addition, it needs to focus on the supply capacity and product price of different suppliers.

(6) Rules of scientific rationality:

The establishment of the evaluation and selection index system needs to be scientific and reasonable, and the index system needs to use the combination of qualitative index and quantitative index. In addition, we need to determine the size of the index system according to the needs of enterprises; otherwise, the operation process will be too complex.Reasonable supplier level and standard is one of the preconditions for selecting suitable suppliers to effectively reduce supply risk.In general, the stronger the 
enterprise's comprehensive strength is, the higher the supply chain performance level is $[9,10]$, and which can effectively resist external risk factors, with long-term and stable cooperation ability. If the supplier does not grasp the strength of the whole supply chain, it will lead to the overall stability of the supply chain. According to the strength of different suppliers to select is the most effective way of development, selecting strong and stable suppliers can effectively promote the development of enterprises, so that the two can establish a long-term cooperative relationship.In addition, in the process of selecting stable suppliers, enterprises pay more attention to the attitude of suppliers, focusing on the attitude of suppliers to the cooperation between them. When the candidate suppliers are not unique, it can provide multiple supply chains, which can effectively reduce the risk of uncertainty in the cooperation process.According to the supplier selection criteria and the corresponding evaluation factors, different enterprises use Figure 2 to select suppliers. The specific operation steps are as follows:

(1) Identification of enterprise needs:

Enterprises and suppliers need to establish a stable and long-term cooperative relationship. They need to comprehensively analyze the market competition environment faced by enterprises at present, analyze the current operation status of suppliers and the defects in the material supply process of enterprises, and use them as the basis for determining the current demand for raw materials of enterprises [11]. In order to further determine whether an enterprise can establish a purchasing relationship with the supplier, it is necessary to adjust the cooperation mode with the supplier according to the actual development of the enterprise.

(2) Identification of alternative suppliers:

The process of selecting suppliers is not only a simple process of evaluation but also a process of reorganization and reengineering of various departments and suppliers. Therefore, on the premise of establishing the final evaluation criteria, each production enterprise needs to determine the suppliers that meet the basic needs of the enterprise from a large number of optional suppliers [12], which are also the potential alternative suppliers of the enterprise in the future. When each candidate supplier meets the minimum development level of the enterprise, it has the opportunity to establish a cooperative relationship with the enterprise. Production enterprises are using certain evaluation systems and evaluation methods to comprehensively evaluate each candidate supplier so as to obtain the best supplier.

(3) Establishment of the evaluation index system of suppliers:

The evaluation index system of suppliers mainly refers to the process of a comprehensive evaluation of alternative suppliers by manufacturing enterprises. The system is established by combining the subordinate relationship and hierarchical structure relationship between enterprises and suppliers.

(4) Determination of the evaluation expert group:

Enterprises invite experts and relevant people to conduct a comprehensive evaluation on suppliers $[13,14]$, among which professional members mainly include procurement, management, and other departments of the enterprise. In order to enhance the scientificity and rationality of the evaluation results, it is necessary to set up an expert evaluation group.

(5) Determination of supplier evaluation method:

The members of the expert evaluation group need to select the final evaluation method and supplier selection standard according to the development of the enterprise and the characteristics of the raw materials. Among them, the selected evaluation method should be in line with the actual needs of enterprise development at this stage as far as possible. In the case of reducing the subjective impact, it also needs to have certain operability.

(6) Comprehensive evaluation of suppliers:

Combined with the production and operation information of suppliers, the most suitable evaluation method for enterprise development needs is selected.

(7) Determination of the optimal number of suppliers: The number of suppliers selected by the enterprise brings different degrees of risk to the later production and development of the enterprise. The more the number of suppliers is, the smaller the probability of raw material shortage is.

(8) Implementation of supplier partnership:

After the enterprise determines the supplier, it needs to form a cooperation relationship with the supplier by using a legal relationship to determine the relevant cooperation funds.

Usually, an enterprise has multiple suppliers. When the supply of any supplier is unexpected, it can fill the vacancy of raw materials from other suppliers. The more suppliers an enterprise has, the less risk it will face. However, in order to coordinate the management of enterprises, it needs to pay the corresponding management costs. When enterprises determine the optimal number of suppliers, they need to comprehensively measure the supply risk and the management cost they need to pay $[15,16]$.

In order to facilitate the analysis of the problem, it needs to make the following assumptions: represents the set of available suppliers; represents the enterprise to select suppliers; represents the set of enterprise to select suppliers; represents the management and operation costs to be paid for the selection of supplier $i$; represents the risk that an enterprise faces when selecting suppliers; and represents the management cost function that an enterprise needs to pay in order to manage suppliers. The specific expressions are as follows: 


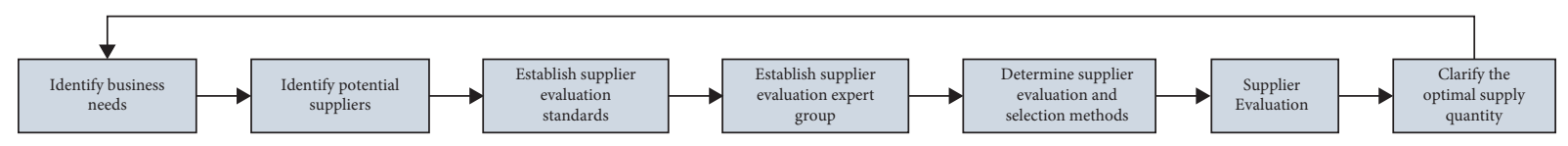

Figure 2: Basic steps of supplier selection.

$$
C_{O}\left(S_{n}\right)=a+\sum_{i \in S_{n}} b_{i}
$$

where $a$ is a constant greater than 0 , which mainly represents the fixed cost of managing suppliers, so $C_{O}\left(S_{n}\right)$ is a monotone increasing function.

$L$ represents that when all suppliers of an enterprise fail at the same time and cannot supply goods normally, it will bring certain economic losses to the enterprise, among which

$$
\left\{\begin{array}{l}
E(L)=\mu_{L} \\
\operatorname{var}(l)=\sigma l^{2}
\end{array}\right.
$$

Considering the risk, $C_{s}\left(S_{n}\right)$ represents the loss cost caused by the failure of suppliers when an enterprise selects $n$ suppliers; $C\left(S_{n}\right)$ represents the total cost of risk loss faced by an enterprise when selecting $n$ suppliers [17]. At the same time, it needs to set the following variable forms:

$$
\begin{aligned}
X & = \begin{cases}1, & \text { represents the probability of common time occurrence } p, \\
0, & \text { otherwise, }\end{cases} \\
Y_{i} & = \begin{cases}1, & \text { represents the supplier is unable to supply goods due to failure, } \\
0, & \text { otherwise. }\end{cases}
\end{aligned}
$$

Through the above variables, we can obtain

$$
\left\{\begin{array}{l}
p(X=1)=p_{a} \\
p\left(Y_{i}=1\right)=p_{i}
\end{array}\right.
$$

In the process of establishing the optimal model of primary and secondary school uniform's raw material supply chain based on the internet of things, it needs to analyze the risk problems, so it needs to make some reasonable assumptions first, which will help further study the problems that need to be solved.

When an enterprise has $n$ suppliers, the probability of supply risk [18] is as follows:

$$
P_{n}(D)=P_{a}+\left(1-P_{a}\right) \prod_{i \in S_{n}} p_{i}
$$

When an enterprise selects two suppliers at the same time, the risk probability faced by the enterprise can be expressed as follows:

$$
P_{2}(D)=\frac{P_{a}+\left(1-P_{a}\right) P_{1}}{P_{2}}
$$

Compared with the situation of only one supplier, that is,

$$
P_{1}(D)-P_{2}(D)=\left\{\begin{array}{l}
P_{a}+\left(1-P_{a}\right) P_{1}-\left\{\frac{P_{a}+\left(1-P_{a}\right) P_{1}}{P_{2}}\right\} \\
\left(1-P_{a}\right) P_{1}\left(1-P_{a}\right) P_{1} P_{2} \\
\left(1-P_{a}\right) P_{1}\left(1-P_{2}\right) .
\end{array}\right.
$$

When $P_{a} \in(0,1), P_{2} \in(0,1)$, it is obvious that the following can happen:

$$
P_{1}(D)-P_{2}(D)=\left(1-P_{a}\right) P_{1}\left(1-P_{2}\right) .
$$

It can be proved by formula (8) that when an enterprise has two suppliers at the same time, the risk probability faced by the enterprise is significantly lower than that with one supplier.

Through the previous analysis, we can see that:

$$
C\left(S_{n}\right)=\left\{\begin{array}{l}
P_{n}(D)\left[L+C_{O}(n)\right]+\left[1-P_{n}(D)\right] C_{O}(n) \\
C_{O}(n)+L\left[P_{a}+\left(1-P_{a}\right) P_{1} P_{2} \ldots P_{n}\right]
\end{array}\right.
$$

After the above analysis, the following models are set up from the perspective of the enterprise's expected risk minimization [19]:

Through the definition of related variables, the loss caused by the failure of all suppliers can be expressed in the following form:

$$
L=L\left(S+(1-S) \prod_{i \in S_{n}} p_{i}\right)
$$

The loss caused by the failure of some suppliers can be expressed in the following form:

$$
l(1-S)=\left(1-\prod_{i \in S_{n}} p_{i}-\prod_{i \in S_{n}}\left(1-P_{i}\right)\right) .
$$

When an enterprise selects $n$ suppliers, the potential risk in the enterprise memory will cause the suppliers to be unable to supply, and the calculation formula of the loss is as follows: 


$$
C_{s}\left(S_{n}\right)=L\left(S+(1-S) \prod_{i \in S_{n}} p_{i}\right)+l(1-S)\left(1-\prod_{i \in S_{n}} p_{i}-\prod_{i \in S_{n}}\left(1-P_{i}\right)\right) .
$$

In the process of enterprise management, we need to coordinate the cost of each supplier to get the total risk cost of selecting $n$ suppliers, namely,

$$
C\left(S_{n}\right)=\left\{\begin{array}{l}
C_{O}\left(S_{n}\right)+C_{s}\left(S_{n}\right) \\
a+\sum_{i \in S_{n}} b_{i}+L\left(S+(1-S) \prod_{i \in S_{n}} p_{i}\right)+\left(1-\prod_{i \in S_{n}} p_{i}-\prod_{i \in S_{n}}\left(1-p_{i}\right)\right)
\end{array}\right.
$$

Combined with the previous random variables, the following formula can be obtained:

$$
\begin{aligned}
E\left(C_{O}\left(S_{n}\right)\right)=\left\{\begin{array}{l}
E\left(L\left(S+(1-S) \prod_{i \in S_{n}} p_{i}\right)+l(1-S)\left(1-\prod_{i \in S_{n}} p_{i}-\prod_{i \in S_{n}}\left(1-p_{i}\right)\right)\right) \\
L\left(P_{a}+\left(1-P_{a}\right) \prod_{i \in S_{n}} p_{i}\right)+l\left(1-p_{a}\right)\left(1-\prod_{i \in S_{n}} p_{i}-\prod_{i \in S_{n}}\left(1-p_{i}\right)\right),
\end{array}\right. \\
\operatorname{Var}\left(C_{O}\left(S_{n}\right)\right)=\left\{\begin{array}{l}
\operatorname{var}\left(a+\sum_{i \in S_{n}} b_{i}\right) \\
\sum_{i \in S_{n}}\left(\sigma_{i}^{2}-\mu_{i}^{2}\right), \\
\operatorname{Var}\left(C_{s}\left(S_{n}\right)\right)=
\end{array}\right. \\
\sigma_{L}^{2}\left(P_{a}+\left(1-P_{a}\right) \prod_{i \in S_{n}} p_{i}\right)+\sigma_{l}^{2}\left(1-P_{a}\right) \prod_{i \in S_{n}} p_{i}-\prod_{i \in S_{n}}\left(1-p_{i}\right)-E\left(C_{O}\left(S_{n}\right)\right),
\end{aligned}
$$

where

$$
\begin{gathered}
E\left(C\left(S_{n}\right)\right)=\left\{\begin{array}{l}
E\left(C_{O}\left(S_{n}\right)\right)+C_{s}\left(S_{n}\right) \\
E\left(C_{O}\left(S_{n}\right)\right)+E\left(C_{s}\left(S_{n}\right)\right),
\end{array}\right. \\
\operatorname{Var}\left(C\left(S_{n}\right)\right)=\left\{\begin{array}{l}
\operatorname{var}\left(C_{O}\left(S_{n}\right)\right)+C_{s}\left(S_{n}\right) \\
\operatorname{var}\left(C_{O}\left(S_{n}\right)\right)+E\left(C_{s}\left(S_{n}\right)\right) .
\end{array}\right.
\end{gathered}
$$

Combined with the above analysis, under the environment of the internet of things, we can build the following optimization model of primary and secondary school uniform's raw material supply chain, and the specific expression is as follows:

$$
S_{n}=\min E\left(C\left(S_{n}\right)\right)+\theta \sqrt{\operatorname{var}\left(C\left(S_{n}\right)\right)} .
$$

2.2. Solution of the Model. The improved genetic algorithm is used to solve the optimization model of the raw material supply chain of primary and secondary school uniform established in Section 2.1. The operation process of a simple genetic algorithm is shown in Figure 3.
However, the traditional genetic algorithm is apt to be nonstandard and inaccurate in coding. Because a single genetic algorithm code cannot fully express the constraints of the optimization problem, it is necessary to consider the threshold of the infeasible solution, thus increasing the workload and time. Because the basic genetic algorithm has some shortcomings, the improved genetic algorithm is used to solve the model, and the gene is set to represent the only alternative selected by node $i$. Through the coding technology based on integer and sequence $[20,21]$, the chromosome can be expressed in the following form, as shown in Figure 4 .

The chromosome encoded by the above rules not only can reflect the chain structure but also can facilitate chromosome genetic operation and meet the corresponding constraints.

A better initial population can improve the search speed and precision. The fitness function is designed by fitness allocation based on ranking, and the population is ranked according to the value of the objective function. The fitness value of the population only depends on the order of 


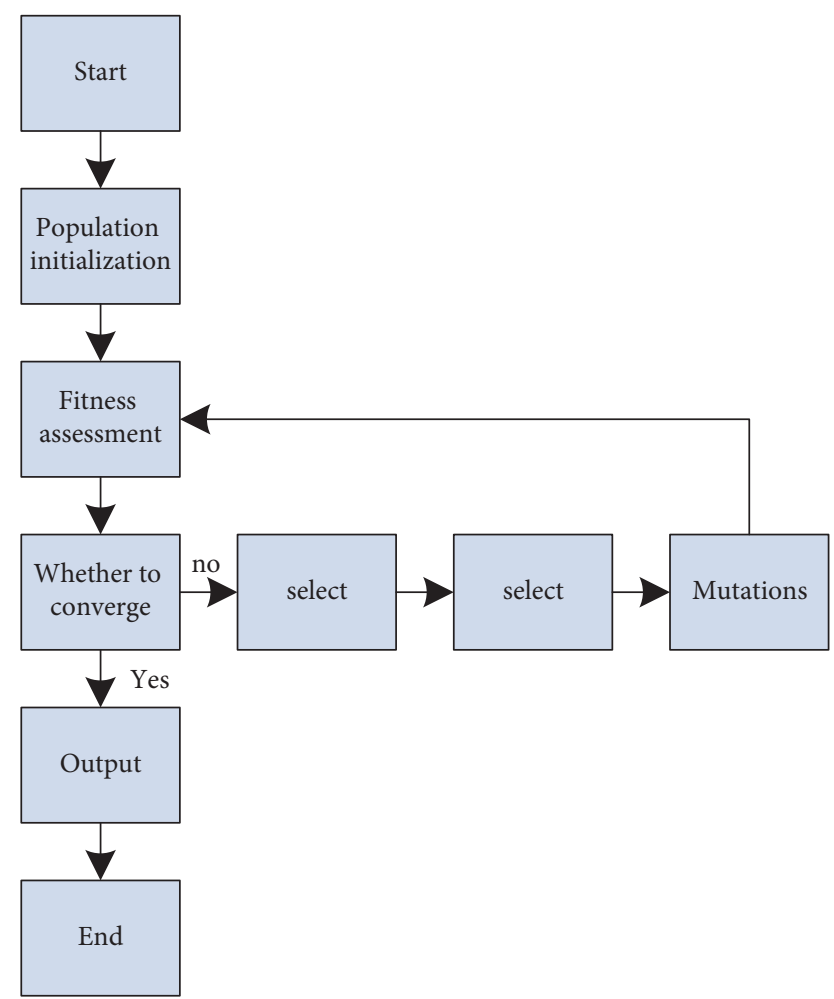

FIGURE 3: Operation flow chart of basic genetic algorithm.

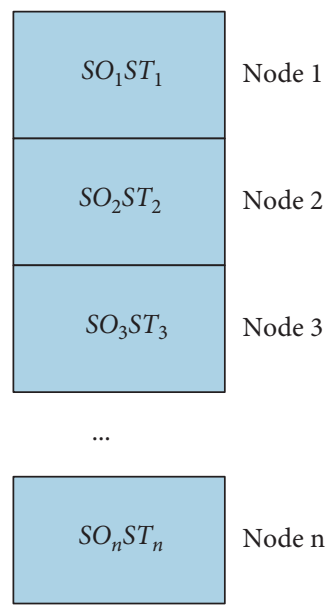

FIGURE 4: Diagram chromosome coding.

individuals in the population but not the actual value of the target. Based on linear or nonlinear sorting fitness allocation, it is necessary to add a population uniform scale to the sorting to provide a simple and effective method for pressure control and obtain better robustness [22]. The nonlinear individual fitness can be expressed in the following form:

$$
f(i)=2-s p+\frac{2(s p-1)(i-1)}{M-1} .
$$

Through elite selection and random traversal strategy, firstly, the fitness values are sorted from good to bad. Elite selection strategy uses individuals with the best fitness value in the target population to copy all to the next generation population, to ensure that the final result is the best individuals in the genetic algorithm.

Figure 5 shows the specific operation process of the model solution.

(1) The structure, demand, and genetic parameters of the supply chain are set, and the initialization rules and the initial population are proposed. Then the population is optimized by the pretreatment method.

(2) The objective function of the population is calculated, and the different fitness is calculated by the linear calibration method with given selection pressure.

(3) It determines whether the convergence standard is reached. Assuming that the specified standard is reached, the final result will be output; otherwise, go to step (4).

(4) The optimal elites are retained by the elitist strategy, and they are put into the elitist pool [23-25]. The individuals whose population size is equal to the size of the parent population minus are selected by random traversal and directly put into the cross pool.

(5) Through the single-point crossover strategy, the population in the crossover pool is crossed and put into the mutation pool after repair.

(6) The population in the mutation pool is mutated by the ergodic operator.

(7) The mutated populations are merged and treated by the population pretreatment method and then return to step (2).

\section{Simulation Experiment}

In order to verify the comprehensive effectiveness of the proposed model based on the internet of things for the raw materials supply chain of primary and secondary school uniform, experiments are carried out in a computer with the environment of Windows 10 system, Intel (R) Core (TM) i78400, 2.81 GHz CPU and $3.89 \mathrm{~GB}$ memory capacity.

3.1. Raw Materials Supply Chain Cost of Primary and Secondary School Uniform (Yuan). In the experiment, three models are selected as comparison methods, which are models in references [2-4]. In order to verify the effectiveness of the proposed model, we take the raw materials supply chain cost of primary and secondary school uniform as the test index. The specific experimental comparison results are shown in Figure 6.

By analyzing the experimental data in Figure 6, it can be seen that with the continuous increase of the number of test samples, the cost of each model shows an upward trend. The model built in reference [2] has a minimum cost of 2,600 yuan and a maximum cost of 5,400 yuan. The cost of the primary and secondary school clothing raw material supply chain of the model constructed by references [3] and [4] is higher, and the highest cost has reached nearly 700 yuan. 


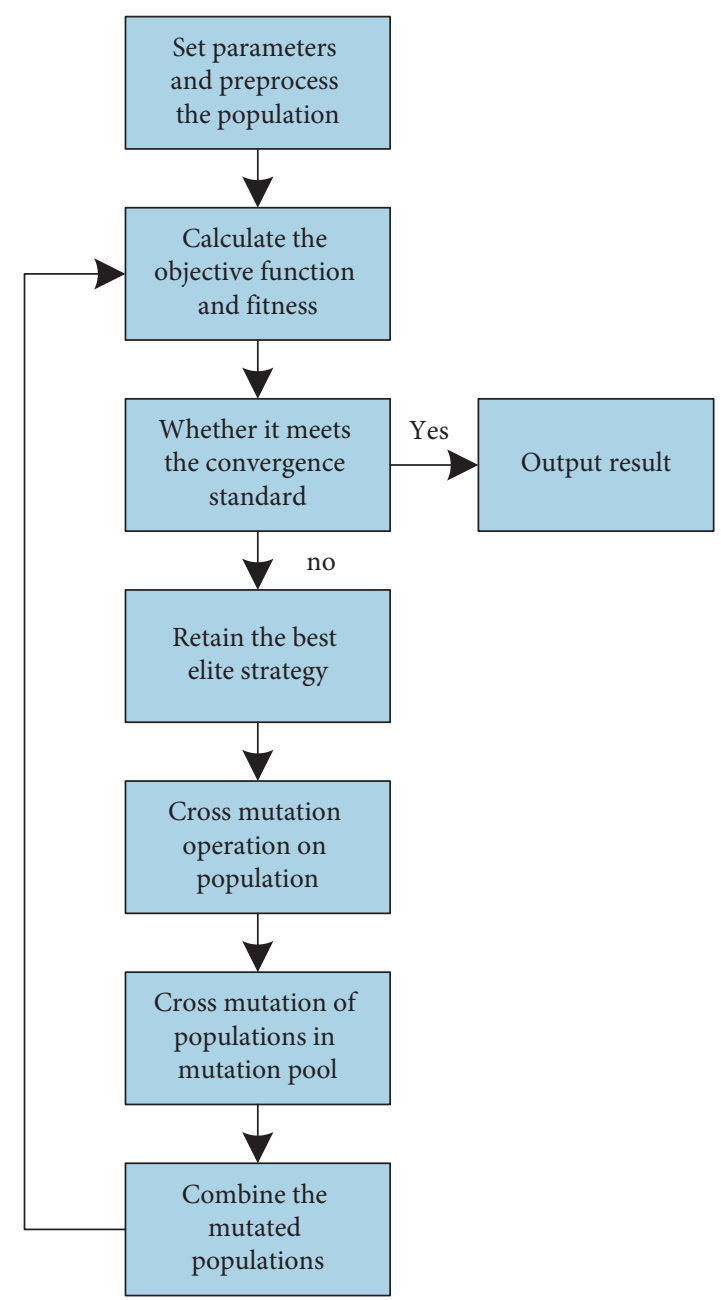

FIGURE 5: Flow chart of the model solution.

Compared with the other three models, the cost of the primary and secondary school clothing raw material supply chain of the proposed model is significantly lower, and the highest cost value is still less than 500 yuan. The main original flavor of this application advantage is: in the process of model selection, the proposed model uses the improved genetic algorithm to solve the model, effectively improves the disadvantages of the traditional genetic algorithm, and makes the cost of the primary and secondary school service raw material supply chain of the whole model significantly lower.

3.2. Asset Utilization Rate of Primary and Secondary School Uniform's Raw Material Supply Chain (\%). On the basis of the above analysis, the following experimental tests set the asset utilization rate of primary and secondary school uniform's raw material supply chain as the evaluation index, and Figure 7 is the comparison results of the asset utilization rate of four models in primary and secondary school uniform's raw material supply chain.

By analyzing the experimental data in Figure 7, it can be seen that compared with other reference models, the asset utilization rate of primary and secondary school clothing raw material supply chain constructed by the model is higher. During 350 iterations, the fluctuation range of utilization rate is $75 \%$ 92\%. The numerical results show that the model meets the application requirements. This is because after the proposed model is established, the improved genetic algorithm is used to solve the model to obtain the optimal primary and secondary school clothing raw material supply chain, which makes the overall asset utilization rate significantly higher than the other three models. At the same time, it also fully verifies the correctness of using the improved genetic algorithm to solve the model.

3.3. Execution Efficiency (\%). In order to fully verify the superiority of the proposed model, the following experimental tests compare the execution efficiency of three different models. The specific experimental results are shown in Table 1.

By analyzing the experimental data in Table 1 , it can be seen that the execution efficiency of the proposed model is significantly higher than that of the other three models. The highest execution efficiency of the model constructed in reference [2] is $96.2 \%$; the highest execution efficiency of the model constructed in reference [3] is $95.5 \%$; the highest 


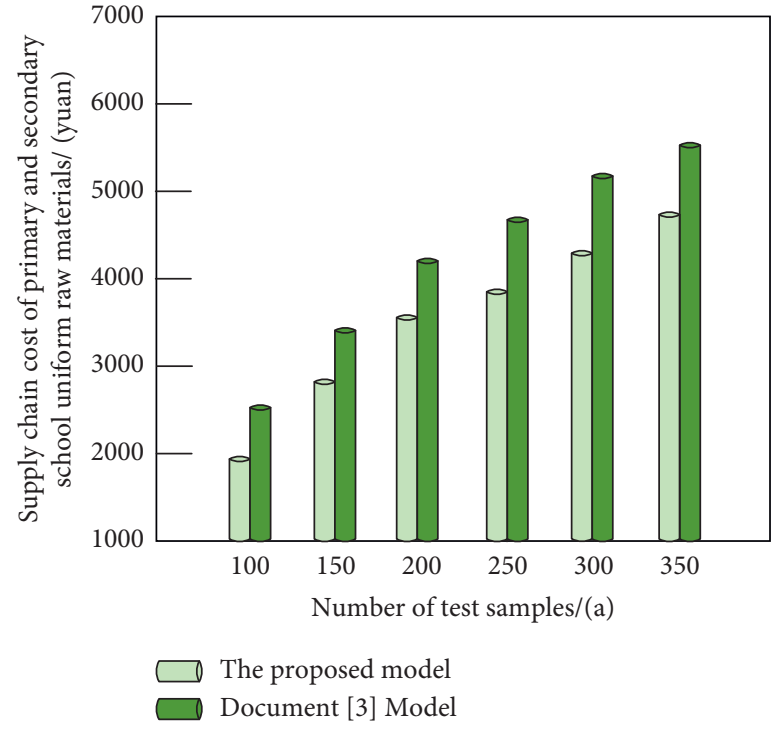

(a)

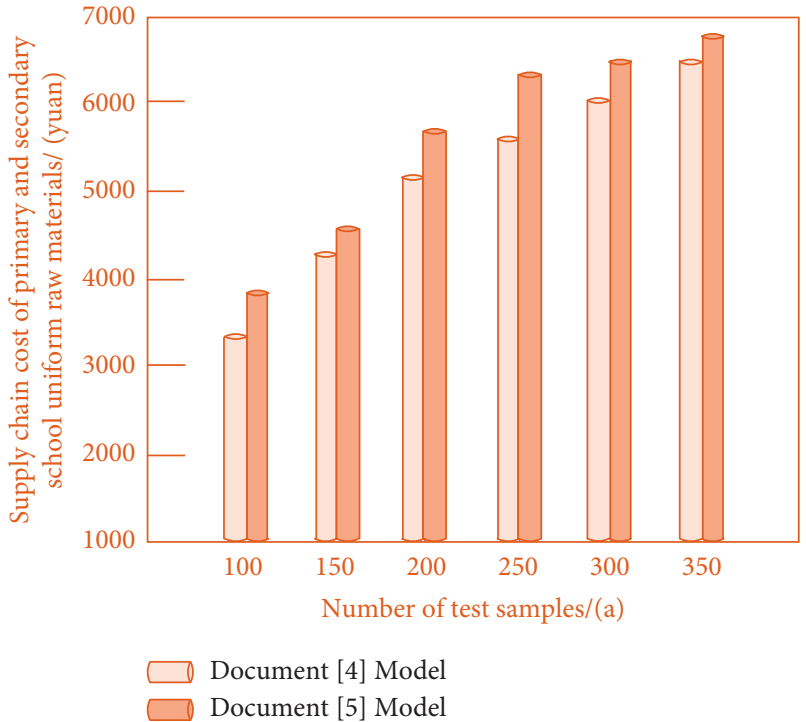

(b)

FIGURE 6: Comparison results of raw materials supply chain cost of primary and secondary school uniform with different models.

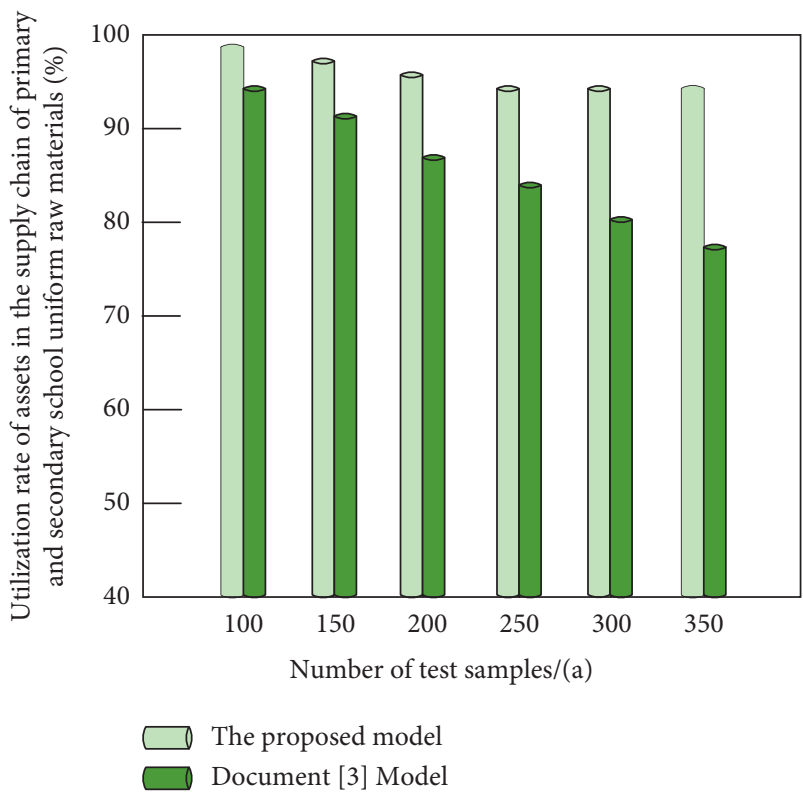

(a)

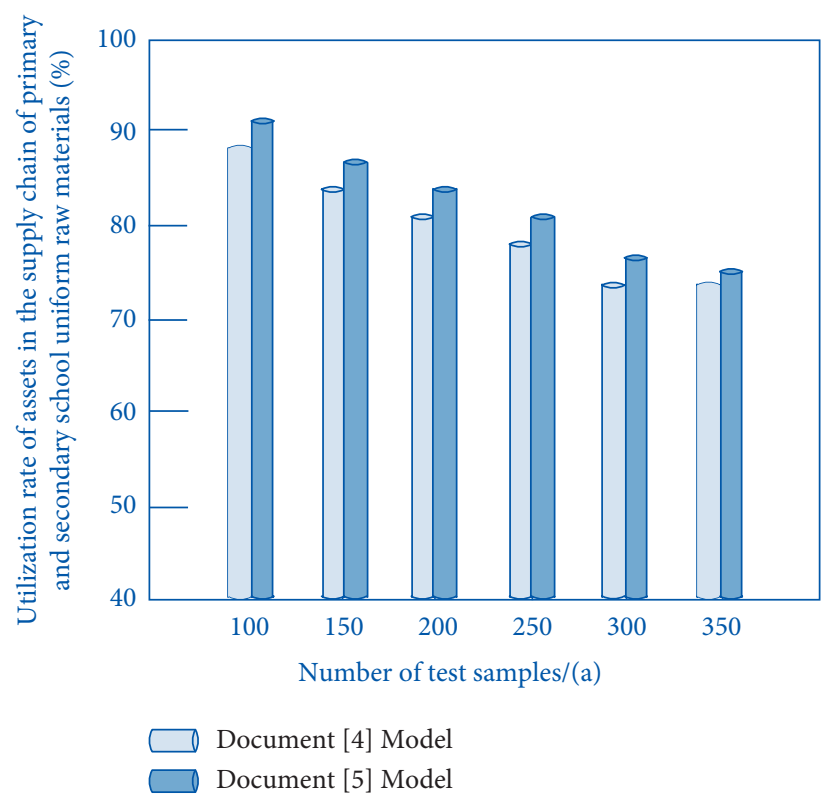

(b)

FIgURe 7: Comparison results of the asset utilization rate of primary and secondary school uniform's raw material supply chain with different models.

TABLE 1: Comparison results of the execution efficiency of three different methods.

\begin{tabular}{lcccc}
\hline \multirow{2}{*}{ Number of experiment (times) } & \multicolumn{3}{c}{ Execution efficiency (\%) } \\
& The proposed model & Model of reference [2] & Model of reference [3] & Model of reference [4] \\
\hline 5 & 98.6 & 96.2 & 95.5 & 94.3 \\
10 & 97.3 & 95.1 & 94.6 & 93.1 \\
15 & 96.4 & 94.3 & 88.1 & 90.2 \\
20 & 96.5 & 92.0 & 86.2 & 87.7 \\
25 & 95.2 & 91.1 & 85.4 & 85.2 \\
30 & 95.3 & 90.3 & 84.2 & 83.5 \\
35 & 94.8 & 88.4 & 83.0 & 7.3 \\
40 & 94.1 & 87.0 & & 79.4 \\
\hline
\end{tabular}


execution efficiency of the model constructed in reference [4] is $94.3 \%$; and the highest execution efficiency of the model in this paper is $98.6 \%$. This is mainly because the proposed model improves the traditional genetic algorithm, comprehensively improves its shortcomings, and enhances its overall performance so as to obtain the optimal primary and secondary school clothing raw material supply chain and improve the execution efficiency of the model.

\section{Conclusion}

The existing models have the following problems: the increase of primary and secondary school uniform's raw material supply chain cost, the decrease of asset utilization, and execution efficiency of primary and secondary school uniform's raw material supply chain. Therefore, this paper proposes a model based on the internet of things for the raw materials supply chain selection of primary and secondary school uniform. The test results show that the proposed model can effectively reduce the cost of primary and secondary school uniform's raw material supply chain and improve the asset utilization and execution efficiency of primary and secondary school uniform's raw material supply chain. The application of the genetic algorithm in resource comprehensive optimization will greatly improve the scientificity and timeliness of network planning. However, the type of raw material supply chain in this study is still vague, which mainly solves the problem of selecting the best supply chain, but the difference of supply modes between different types of enterprises has not been discussed deeply, and there is no analysis on the operation of raw material supply enterprises so as to provide theoretical reference and method guidance for further improving management and enhancing comprehensive strength.

In the future, we will focus on the following aspects:

(1) There are many factors that cause the flexibility of suppliers. In the future, we will further consider the internal flexibility of suppliers and the flexibility of product renewal and continue the next research work.

(2) Because the price and demand are completely different in different periods, it is still a huge challenge to solve the model. In the future, more optimization algorithms will be introduced into the model.

(3) There is also an inventory problem in the model, that is, the enterprise needs to select a certain amount of raw materials to deal with the uncertainty of each enterprise's demand, which is also a problem worthy of study.

(4) It should expand the scope of application of the model and strengthen the comprehensive performance of the model.

\section{Data Availability}

All the data contained in this paper were generated by the authors' own experiment.

\section{Conflicts of Interest}

The authors declare that there are no conflicts of interest regarding the publication of this paper.

\section{Acknowledgments}

This work was supported by Educational Science Research Project of Shanghai (No: C20076) and Talent Studio about Culture and Education of Shanghai.

\section{References}

[1] J. B. Hu, "SCOR model helps supply chain improvement," Enterprise Management, vol. 446, no. 10, pp. 84-87, 2018.

[2] X. H. Qin, "Research on logistics network optimization of existing supply chain based on carbon trading," Application Research of Computers, vol. 05, no. No.307, pp. 100-104, 2017.

[3] L. L. Chen, P. Guo, and E. Han, "Supply chain decisionmaking optimization model based on fuzzy theory under carbon tax," Computer Integrated Manufacturing Systems, vol. 023, no. 004, pp. 860-866, 2017.

[4] X. H. Wang, F. Li, and L. Liang, "Deconstruction and structural optimization model of disaster relief material supply network," China Management Science, vol. 25, no. 001, pp. 139-150, 2017.

[5] A. Allman, C. Lee, M. Martín, and Q. Zhang, "Biomass wasteto-energy supply chain optimization with mobile production modules," Computers \& Chemical Engineering, vol. 150, no. 10, Article ID 107326, 2021.

[6] G. Leonzio, P. U. Foscolo, and E. Zondervan, “An outlook towards 2030: optimization and design of a CCUS supply chain in Germany," Computers \& Chemical Engineering, vol. 125, no. JUN.9, pp. 499-513, 2019.

[7] M. Rocha de Paula, N. Boland, A. T. Ernst, A. Mendes, and M. Savelsbergh, "Throughput optimisation in a coal export system with multiple terminals and shared resources," Computers \& Industrial Engineering, vol. 134, no. AUG, pp. 37-51, 2019.

[8] M. Hajian Heidary and A. Aghaie, "Risk averse sourcing in a stochastic supply chain: a simulation-optimization approach," Computers \& Industrial Engineering, vol. 130, no. APR, pp. 62-74, 2019.

[9] L. Hao, D. W. Hu, and C. Li, "Purchasing management supplier selection and order allocation in enterprise supply chain under T-JIT environment," Journal of Highway and Transportation Research and Development (English Edition), vol. 12, no. 3, pp. 80-89, 2018.

[10] Z. P. Tong, Q. G. Xu, and L. Ren, "Multi-layer logistics warehouse facility supply chain balance optimization management simulation," Computer Simulation, vol. 35, no. 003, pp. 361-364, 2018.

[11] M. Feitó-Cespón, Y. Costa, M. S. Pishvaee, and R. CespónCastro, "A fuzzy inference based scenario building in twostage optimization framework for sustainable recycling supply chain redesign," Expert Systems with Applications, vol. 165, no. 4, Article ID 113906, 2020.

[12] Y. M. Pan, Y. J. Wang, and M. Z. Lai, "Credit risk prediction of supply chain financing enterprises based on IG-SVM model," Journal of Nanjing University of Science and Technology (Natural Science Edition), vol. 44, no. 01, pp. 117-126, 2020.

[13] H. J. Zhao, "Research on operation model and realization ways of supply chain service in railway logistics park," Railway Transport and Economy, vol. 40, no. 010, pp. 33-37, 2018. 
[14] I. I. Almaraj and T. B. Trafalis, "Affinely adjustable robust optimization under dynamic uncertainty set for a novel robust closed-loop supply chain," Computers \& Industrial Engineering, vol. 145, Article ID 106521, 2020.

[15] H. B. Yu, N. Na, and Z. J. Tang, "Mean-CVaR retailer's supply chain service decision and coordination contract," Journal of Operations Research, vol. 24, no. 3, pp. 91-104, 2020.

[16] A. Akgul and S. U. Seckiner, "Optimization of biomass to bioenergy supply chain with tri-generation and district heating and cooling network systems," Computers \& Industrial Engineering, vol. 137, no. Nov, pp. 106017.1-106017.14, 2019.

[17] L. G. Wu and L. Wen, "Low-carbon supplier selection method based on two-dimensional two-tuple semantics and fuzzy AHP-TODIM," Operations Research and Management, vol. 026, no. 003, pp. 7-16, 2017.

[18] J. Zhang, K. Kang, X. G. Wei, and Z. Y. Zhang, "Research on the impact of institutional environment and risk perception on the choice of supply chain network governance models," Management Review, vol. 032, no. 001, pp. 275-285, 2020.

[19] C. H. Qian and J. T. Wu, "Supplier selection model based on Bayesian network and TOPSIS," Industrial Technology Economics, vol. 04, no. 294, pp. 128-133, 2018.

[20] Z. H. Luo, M. F. Zhong, and J. He, "Research on green building parts supplier selection strategy based on improved Kent index method," Science \& Technology Progress and Policy, vol. 035, no. 024, pp. 76-80, 2018.

[21] J. L. Jiao and G. C. Sang, "Real estate enterprise supplier selection under value-added tax," Finance and Accounting, vol. 000, no. 023, pp. 50-52, 2017.

[22] A. Hm, A. Nh, and B. Tmc, "Reverse supply chain systems optimization with dual channel and demand disruptions: sustainability, CSR investment and pricing coordination," Information Sciences, vol. 503, no. C, pp. 606-634, 2019.

[23] Q. X. Zhang, J. J. She, and S. Ye, "Selection of PC component suppliers for prefabricated construction based on GRAPVIKOR," Journal of Civil Engineering and Management, vol. 37, no. 1, pp. 165-172, 2020.

[24] E. Chinello, Z. Herbert-Hansen, and W. Khalid, "Assessment of the impact of inventory optimization drivers in a multi-echelon supply chain: case of a toy manufacturer," Computers \& Industrial Engineering, vol. 141, no. Mar., pp. 106232.1-106232.22, 2020.

[25] J.-Y. Li, Q.-Q. Zhou, and P.-P. Yin, "Smart and IoT-based coupling and coordination development for financial and logistics industries," Mobile Information Systems, vol. 2021, Article ID 3227408, 11 pages, 2021. 